\title{
Determinants of Long Acting Reversible Contraception Method Use among Mothers in Extended Postpartum Period, Durame Town, Southern Ethiopia: A Cross Sectional Community Based Survey
}

\author{
Yirga Ewnetu Tamrie1, Ewenat Gebre Hanna2, Mesele Damte Argaw ${ }^{3 *}$ \\ ${ }^{1}$ EngenderHealth Ethiopia, Hawassa, Ethiopia \\ ${ }^{2}$ Addis Continental Institute of Public Health, Addis Ababa, Ethiopia \\ ${ }^{3}$ Private Health Sector Program, Addis Ababa, Ethiopia \\ Email: yewnetu@gmail.com, gewenat@gmail.com, ${ }^{*}$ mdamte5@gmail.com
}

Received 6 September 2015; accepted 17 October 2015; published 20 October 2015

Copyright (C 2015 by authors and Scientific Research Publishing Inc.

This work is licensed under the Creative Commons Attribution International License (CC BY). http://creativecommons.org/licenses/by/4.0/

\section{(c) (i) Open Access}

\section{Abstract}

Background: After a live birth, there is much unsatisfied interest in, and unmet family planning need for contraception. Waiting at least for 24 months before attempting the next pregnancy was recommended to reduce the risk of adverse maternal, perinatal and infant outcomes. The purpose of this study was to assess the determinants of long acting reversible contraception method use among mothers in extended postpartum period in Durame Town, Southern Ethiopia. Methods: A community based cross sectional study was conducted in Durame Town, Southern Ethiopia in December, 2014. Systematic random sampling technique was employed to recruit a total 460 study participants. Structured and pretested questioner was used to collect the data. Descriptive statistics was employed to characterize the study population using frequencies and proportions. Bivariate logistic regression analysis was conducted to identify all possible factors affecting utilization of LARC method. Multivariable logistic regression model was developed to control the confounding variables. Adjusted Odds Ratio (AOR) with 95\% Confidence Interval (CI) was computed in identifying the real factors associated with use of LARC methods. Results: In this study we found that the prevalence of LARC method use among mothers during their extended postpartum period was $36.7 \%$ (95\%CI: $32.2,41.0)$. The unmet family planning need of mothers in the extended postpartum period was $123(27.9 \%)$. The odds of using LARC by literate mother were four fold higher than their counterpart illiterate mothers (AOR 4.09 95\%CI: 1.68, 9.58, $P$ value $<0.001$ ). The odds

\footnotetext{
${ }^{*}$ Corresponding author.
} 
of mother who had pervious experiences of using LARC were up to eight folds higher than mother never used LARC methods (AOR 7.84 95\% CI: 3.78, 16.23, $P$ value< 0.001 ). Mother who received counseling service on LARC methods during delivery was up to three times more likely to utilize the services than not counseled (AOR 3.29 95\% CI: 1.53, 7.03, $P$ value $<0.001$ ). And odds of mothers who received counseling service on LARC during immediate postpartum period were up to five fold more likely to opt method than never got the counseling service (AOR $4.5595 \% \mathrm{CI}: 1.94$, 10.66, $P$ value $<0.001$ ). Conclusions: In the study area, about one third of mothers utilized LARC methods during their extended postpartum period. Another one third of mother had unmet need for family planning. Participant's education, previous history of using LARC methods, receiving counseling services on LARC during delivery and immediate postpartum periods were found major determinant for LARC use. Educating women, providing counseling service on LARC methods during antenatal, delivery and postnatal were recommended.

\section{Keywords}

Extended Postpartum, Long Acting Reversible Contraception, Method Use, Determinants, Ethiopia

\section{Introduction}

Closely spaced pregnancies increase the risks of infants with adverse outcomes such as preterm, low birth weight and small for gestational age. Pregnancy occurring within six months of the last delivery holds a 7.5-fold increased risk for induced abortion, a 3.3-fold increase in miscarriage and a 1.6-fold increased risk of stillbirth [1].

An analysis of Demographic Health Survey (DHS) data from 27 countries showed that two-thirds of women who were within one year of their last birth had an unmet need for contraception, and nearly $40 \%$ of mothers had the plan to use a method in the next 12 months but were not doing so [2]. The study conducted in rural Egypt on pregnancy during breastfeeding showed that conception occurred during the first 6 months of postpartum in $4.4 \%$ cases, and this figure improved to $15.1 \%$ before resumption of menstruation [3].

Promotion of contraception in countries with high birth rates has the potential to reduce poverty, hunger and avert $32 \%$ of all maternal deaths and nearly $10 \%$ of childhood deaths [4]. Every year in sub-Saharan Africa (SSA), approximately 14 million unintended pregnancies occurred and a sizeable proportion was due to poor use of short-term hormonal methods. If $20 \%$ of the 17.6 million women who were using oral or injectable contraceptives want long-term protection and switched to the contraceptive implants, over 1.8 million unintended pregnancies could be averted over a 5-year period [5].

Globally, female sterilization is the most common method of contraception, used by $19 \%$ targeted mothers, followed by 14\% were Intra Uterine Contraceptive Device (IUCD) and 9\% were pill among women aged 15 to 49 years who were married or in a union [6]. However, based on the 2011 Ethiopian Demographic and Health Survey (EDHS) analysis, the use of modern family planning is low. The unmet need among women in extended postpartum period was very high. Utilization rate of modern FP methods among reproductive age group mother includes: $77 \%$ injectable, $10 \%$ implants, $7 \%$ pills, $1 \%$ IUCD, $1 \%$ female sterilization and $1 \%$ condoms [7].

The most effective modern family planning method consists of LARCs which are IUCD and Implants. These methods have multiple advantages over other reversible methods. Most importantly, once in place, they do not require maintenance and their duration of action is long, ranging from 3 to 10 years [8].

According to EDHS (2011), the 12-month contraceptive discontinuation rate for all methods was 37 percent. Among the modern methods, the highest discontinuation rate was for the pill (70 percent), followed by the male condom (62 percent). In contrast, implants have a discontinuation rate of just 5 percent [9]. The contraceptive failure rate among participants using pills, patch, or ring was 4.55 per 100 participant-year, as compared with 0.27 among participants using LARCs [10].

Nationally, Ethiopia strives to improve the utilization rate of modern contraceptives specifically LARCs. As to the knowledge of the investigators, there were no specific studies conducted on determinants of uptake of LARCs among mothers in the extended postpartum period in Ethiopia. Hence, conducting this study was found 
helpful to assess the utilization rate and identify determinants factors for LARC use among mothers in extended postpartum period.

\section{Operational Definitions}

Long acting revisable contraception (LARC) user: women in extended postpartum period who are using either of Implanon, Sino-implant/Jadelle or IUCD at the time of data collection.

Non user of long acting reversible contraception: women in extended postpartum period who are using Lactation Amenorrhea Method (LAM), Pills, Condom, injectable or woman who don't use any contraception method at the time of data collection.

Knowledge about LARC: women in extended postpartum period who know at least one of the LARC methods i.e. Implanon, Sino-implant/Jadelle and IUCD.

Postpartum period is clinically defined as the first 6 weeks following childbirth; for the purpose of family planning "postpartum period" is divided into the following four stages: Post placental, the first ten minutes following delivery of the placenta, the second, Early postpartum: the first seven days following delivery of the placenta, Late postpartum: from one week, to four to six weeks following delivery of the placenta and Extended postpartum; up through twelve months following delivery of the placenta. Post-Partum Family Planning (PPFP) Method use: is the utilization of family planning services within the first 12 months following childbirth to prevent closely spaced and unintended pregnancies [11]. For this study, Extended Postpartum Period; is the period which includes from the 42 to 365 days after delivery.

Immediate Postpartum period: is the period which includes 48 hours to 42 days after deliver.

Family folder: The Family Folder is the central piece of the Community Health Information System (CHIS). Family folder contains standardized integration and simplification to provide information for decision making [12].

\section{Methods}

\subsection{Study Design}

A community based cross sectional study design of quantitative method was used. The study was conducted among mothers, who spent 42 to 365 days after they gave live birth prior to the data collection in Durame town administration, South Ethiopia, in December, 2014.

\subsection{Study Setting}

Durame town is located in Kemebata-Tembaro Zone of South Nations, Nationalities and Peoples Regional State (SNNPRS). The town is located $119 \mathrm{Km}$ away from Hawassa City, Capital City of SNNPRS. The town has three kebeles, smallest government administrative units. Based on the projected 2007 population census, in the years 2014, Durame town has a population of 35,610 (18,162 were females and 17,448 were males) [13]. The number of woman in reproductive age group was 8297 and the estimated number of deliveries was 1233 . The town administration has one hospital, three health centers with high potential health service coverage [14].

\subsection{Sample Size and Sampling Procedure}

The sample size was calculated using single population proportion formula [15]. The following assumption was considered. The prevalence of LARC method use was assumed (P) of 50\%; considering 5\% margin of error (d) and $95 \%$ CI. After considering $20 \%$ non-response rate, the total sample size was estimated to be 460 . All households who have mother with history of birth in the previous one year were identified using the family folder of the Health Centers [14]. The list was served as a sampling frame. Using population proportion to size, allocations of study subjects were made for each kebele. Each study subjects was selected using systematic random sampling techniques using the sampling interval (k) of 3 from each Kebeles.

\subsection{Data Collection Procedures}

The data were collected using a structured questionnaire. The questionnaires were developed according to the objective of the study [9]. Primarily, the questionnaires were prepared in English and translated back to local 
official language (Amharic) to make the communication easy for data collectors. The data collectors were trained nurses working out of Durame town Administration. Using the questionnaire, selected women who spent at least 42 days and not exceeded 365 days after they had given birth were enrolled. Selected study subjects were interviewed house to house by trained data collectors. Data collectors made a sign on the doors of households after data collection to avoid repetition. In the process of data collection, supervisors were assisted the data collectors. One day training was organized for 8 data collectors and two supervisors about the purpose and the overall data collection process to make them familiarize with the questioners. The questionnaire was pre-tested and the necessary amendment was made before the actual filed work.

\subsection{Data Management}

The data collected were checked for completeness and consistency; arrangement made to enter data after each day field work was completed. Data entry was made using Epi-Info version 3.5.3 (Communicable Disease Control (CDC), Atlanta, Georgia, (USA) \& data analysis was done using Statistical Package for Social Science (SPSS) research IBM SPSS version 20.

\subsection{Data Analysis Procedure}

To explain the relationship of relevant variable; univariate analysis was done using frequency and percentage for the first objective. Then, for the second objectives; associations between dependent and independent variables were evaluated using bivariate analysis. The results were presented using Crude Odds Ratios (COR) and 95\% Confidence Intervals (CIs). Those independent variables that showed significant associations were taken to multivariate logistic analysis and the data were analyzed to identify independent predictors by controlling confounding variables. The findings were reported using Adjusted Odds Ratio (AOR) with 95\% Confidence Interval (CI). $P$ value $<0.05$ was considered to determine statistical significance.

\subsection{Ethical Consideration}

Ethical clearance was obtained from Research Review Board of University of Gondar. Permission to conduct this research was granted by the Durame Town Health Officers. Before interviewing; informed consent was obtained from each study participant after getting information on the purpose, objective and benefit of the research. Participants were free to withdraw themselves from participation at any time and name or personal identification was not used on the data collection form to keep participants response confidential

\section{Result}

\subsection{Socio-Demographic Characteristics}

A total of 441, with a response rate of $95.9 \%$, women who spent between 42 to 365 days after they had given birth prior to the study were included in this study. The mean age of the respondent was 27.46 (SD \pm 4.15 ) years. Most of the respondents were married 412 (93.4\%) and majority of the respondent were protestant 335 (76\%) by religion. Slightly higher than one third of the women, 160 (36.3\%) have attended secondary level of education. Three hundred thirteen (71\%) of the respondents were housewives by occupation and 154 (37.3\%) of their husband were self-employed (Table 1).

\subsection{Reproductive History}

The mean number of children with standard deviation (SD) ever born by the study participants was $3.02( \pm 1.8)$. The average age of the index infant was 7.1 (SD \pm 2.9 ) months. The analysis of the birth spacing of women of non-first birth indicated that 105 (30.9\%) of births occurred less than 24 months, 120 (35.3\%) births occurred between 24 to 36 months and 115(33.8\%) births occurred above 36 months after the preceding births.

One hundred (22.7\%) of the current birth were not planned for the time. Of these unplanned births 56 (56\%) of mothers were not using modern contraception. Three hundred twenty one $(72.8 \%)$ of the respondent had a plan to have children in the future whereas 83 (18.8\%) did not have a plan and 37 (8.4\%) of the respondent were undecided about their future child birth. Among those who had a plan to have a child in the future; most of the participants 285 (88.8\%) wants to have a child after 24 months. However, 36 (11.2\%) of the mothers want to have a child within 24 months. 
Table 1. Socioeconomic and demographic characteristics of mothers in extended postpartum period in Durame Town, Southern Ethiopia, 2015.

\begin{tabular}{|c|c|c|}
\hline Variable & Frequency & Percentage (\%) \\
\hline \multicolumn{3}{|l|}{ Age Group ( $N=441)$} \\
\hline $15-24$ & 101 & 22.9 \\
\hline $25-34$ & 305 & 69.2 \\
\hline $35-44$ & 35 & 7.9 \\
\hline \multicolumn{3}{|l|}{ Religion ( $N=441)$} \\
\hline Protestant & 335 & 76.0 \\
\hline Orthodox & 53 & 12.0 \\
\hline Catholic & 43 & 9.8 \\
\hline Muslim & 10 & 2.3 \\
\hline \multicolumn{3}{|l|}{ Marital Status (N = 441) } \\
\hline Married & 412 & 93.4 \\
\hline Separate & 18 & 4.1 \\
\hline Single & 4 & 0.9 \\
\hline Widowed & 4 & 0.9 \\
\hline Divorced & 3 & 0.7 \\
\hline \multicolumn{3}{|l|}{ Educational Status (N = 441) } \\
\hline Primary and less & 200 & 45.4 \\
\hline Secondary & 160 & 36.3 \\
\hline Above secondary & 81 & 18.4 \\
\hline \multicolumn{3}{|c|}{ Education of Husband (N = 338) } \\
\hline Primary and less & 156 & 35.6 \\
\hline Secondary & 139 & 31.7 \\
\hline Above Secondary & 143 & 32.6 \\
\hline \multicolumn{3}{|l|}{ Participants Occupation (441) } \\
\hline Housewives & 313 & 71.0 \\
\hline Self employed & 39 & 8.8 \\
\hline Public servant & 89 & 20.2 \\
\hline \multicolumn{3}{|l|}{ Occupation of Husband (412) } \\
\hline Self employed & 154 & 37.3 \\
\hline Employed & 149 & 36.2 \\
\hline Daily laborer & 59 & 14.3 \\
\hline Farmer & 37 & 9.0 \\
\hline Others (priest, student etc.) & 13 & 3.2 \\
\hline
\end{tabular}

Close to half of mothers 202 (45.8\%) reported as their menstruation was resumed at the time of interview. The majority 176 (87.1\%) participant's menstruation resumed within six months after their recent birth. Three hundred eight one (86.4\%) of the respondents were resumed sexual intercourse at the time of interview of these respondents, 372 (97.6\%) resumed sexual activity within three months after their last birth (Table 2). 
Table 2. Reproductive information of mothers in extended postpartum period, Durame Town, 2015.

\begin{tabular}{|c|c|c|}
\hline Variable & Frequency & Percentage (\%) \\
\hline \multicolumn{3}{|c|}{ Number of children $(N=441)$} \\
\hline 1 Child & 101 & 22.9 \\
\hline 2 - 4 children & 260 & 59.0 \\
\hline 5 and above children & 80 & 18.1 \\
\hline \multicolumn{3}{|l|}{ Birth interval $(\mathrm{N}=340)^{*}$} \\
\hline Less than 24 months & 105 & 30.9 \\
\hline 24 to 36 Months & 120 & 35.3 \\
\hline 36 and above months & 115 & 33.8 \\
\hline \multicolumn{3}{|c|}{ Is the present birth was planned? $(\mathrm{N}=441)$} \\
\hline No & 100 & 22.7 \\
\hline Yes & 341 & 77.3 \\
\hline \multicolumn{3}{|c|}{ Do you have a plan to have a child in the future? $(\mathrm{N}=441)$} \\
\hline No & 83 & 18.8 \\
\hline Undecided & 37 & 8.4 \\
\hline Yes & 321 & 72.8 \\
\hline \multicolumn{3}{|c|}{ Plan to have another child in the future $(N=321)$} \\
\hline Less than 24 months & 36 & 11.2 \\
\hline 24 and above months & 285 & 88.8 \\
\hline \multicolumn{3}{|c|}{ Is your menstruation resumed after recent birth? $(\mathrm{N}=441)$} \\
\hline No & 239 & 54.2 \\
\hline Yes & 202 & 45.8 \\
\hline \multicolumn{3}{|c|}{ Time of resumption of sexual activity $(\mathrm{N}=381)$} \\
\hline Less than 3 months & 364 & 95.5 \\
\hline 3 to 6 months & 16 & 4.2 \\
\hline
\end{tabular}

*Among those who are non-first birth women's.

\subsection{Knowledge of Mothers towards LARC Methods}

Four hundred thirty (97.5\%) of the study participant were ever heard about LARC methods. Among mothers who were reported that they heard about LARC, (92.1\%) were head about Implanon followed by 83\% were about Jadelle, $61.9 \%$ were about IUCD and $44.9 \%$ were about Sino-Implant. The main sources of information were health workers (89.1\%), Health Extension Worker (64.7\%) and mass media (radio or television) (36.5\%). Among the study participants 123 (27.9\%) had ever used LARC family planning method. Of the total study participants; 80 (18.1\%) were used Implanon followed by 38 (8.6\%) Jadelle/Sino implant and 5 (1.1\%) were IUCD (Table 3).

\subsection{Utilization of Maternal Health Service}

Regarding to the uptake of maternal health service, 436 (98.9\%) of the study participant had attended at least a single antenatal care (ANC) for their last pregnancy. Of these 227 (52.1\%) of mothers had received counseling service on LARC methods. Among the respondents who had ANC follow up and received counseling service on LARC; Implanon is the most counseled followed by Sino-Implant/Jadelle and IUCD which were 97.8\%, 85.0\% and 57.3\%, respectively (Table 4). 
Table 3. Knowledge and utilization of LARC methods among mothers in extended postpartum period, Durame town, 2015.

\begin{tabular}{|c|c|c|}
\hline Variable & Frequency & Percentage (\%) \\
\hline \multicolumn{3}{|l|}{ Ever heard of LARC ( $N=441)$} \\
\hline No & 11 & 2.5 \\
\hline Yes & 430 & 97.5 \\
\hline \multicolumn{3}{|l|}{ Source of LARC information* } \\
\hline Health workers & 383 & 89.1 \\
\hline Health extension workers & 278 & 64.7 \\
\hline Friends & 129 & $30 \%$ \\
\hline Television & 157 & 36.5 \\
\hline Radio & 90 & 20.9 \\
\hline Health/women development Army & 84 & $19.5 \%$ \\
\hline Husband & 54 & 12.6 \\
\hline \multicolumn{3}{|l|}{ Ever use of LARC $(\mathrm{N}=441)$} \\
\hline No & 318 & 72.1 \\
\hline Yes & 123 & 27.9 \\
\hline \multicolumn{3}{|c|}{ LARC method used previously $(\mathrm{N}=123)$} \\
\hline Implanon & 80 & 65 \\
\hline Sino-implant/Jadelle & 38 & 30.9 \\
\hline IUCD & 5 & 4.1 \\
\hline \multicolumn{3}{|c|}{ Time of adopting current use of LARC $(\mathrm{N}=164)$} \\
\hline Less than 3 months & 131 & 80.9 \\
\hline 3 to 6 months & 23 & 14.2 \\
\hline 6 and above months & 8 & 4.9 \\
\hline
\end{tabular}

${ }^{*}$ Multiple responses.

Table 4. Maternal health service uptake among mothers in extended postpartum period, Durame town, 2015.

\begin{tabular}{|c|c|c|}
\hline Variable & Frequency & Percent (\%) \\
\hline \multicolumn{3}{|c|}{ ANC follow up $(\mathrm{N}=441)$} \\
\hline No & 5 & 1.1 \\
\hline Yes & 436 & 98.9 \\
\hline \multicolumn{3}{|c|}{ Counseled about LARC during ANC follow up $(\mathrm{N}=436)$} \\
\hline No & 209 & 47.9 \\
\hline Yes & 227 & 52.1 \\
\hline \multicolumn{3}{|c|}{ Place of delivery $(\mathrm{N}=441)$} \\
\hline Home & 15 & 3.4 \\
\hline Health Institution & 426 & 96.6 \\
\hline \multicolumn{3}{|c|}{ Counseled about LARC during Delivery $(\mathrm{N}=\mathbf{4 2 6})$} \\
\hline No & 158 & 37.1 \\
\hline Yes & 268 & 62.9 \\
\hline \multicolumn{3}{|c|}{ Facility visit during immediate postpartum period $(\mathrm{N}=418)$} \\
\hline No & 65 & 15.6 \\
\hline Yes & 353 & 84.4 \\
\hline \multicolumn{3}{|c|}{ Counseled about LARC during immediate postpartum period $(N=307)$} \\
\hline No & 113 & 36.8 \\
\hline Yes & 194 & 63.2 \\
\hline
\end{tabular}


Most of the study participants 426 (96.6\%) had delivered their index infant in the health institutions. Only 15 (3.4\%) of the participants were delivered at home. Among those who were delivered at the health institution, $62.9 \%$ of them were counseled on LARC at the time of delivery. Among those mothers who were counseled LARC during delivery; $8.3 \%$ of them were accepting LARC method before leaving health facility.

Three hundred fifty three (84.4\%) of study participants were visited the health facility during immediate postpartum period. Majority of the participants, 250 (70.8\%) were visited the facility to vaccination service for their child. Only 46 (13\%) of the study participants visited the facility to obtain family planning services during immediate postpartum period. Among those who visited the facility during immediate postpartum period with the exception of participates who visited for family planning services, 194 (63.2\%) of were received counseling service on LARC method at the time of visit. Among those participants counseled during immediate postpartum period, 7 (30.6\%) adopt LARC method at the time of visit.

\subsection{LARC Methods Use}

In this study, 162 (36.7\%; with 95\%CI: 32.2, 41.0) of the study participants were currently using LARC. Among the study participant, 84 (19\%) opted Implanon followed by 47 (10.7\%) Jadelle/Sino Implant and 31 (7\%) IUCD (Figure 1). The unmet need of mothers in the extended postpartum period was 123 (27.9\%). Among the current users, 132 (80.5\%) were women in extended postpartum period opted LARC methods within three months after recent birth. In relation to menstruation, 121 (74.7\%) of current users adopted the method before the resumption of menstruation. The remaining 22 (13.6\%) and 15 (9.3\%) of current users accepted the method after the resumption of and in the same week when menstruation resumed respectively.

Two third 110 (67.1\%) of mothers who uses LARC methods received the services from Health Centers and the remaining 53 (32.3\%) were from Hospital. A little higher than half of the participant 91 (56.1\%) among the current LARC user were opted the method by themselves followed by 42 (25.9\%) of them were by health workers (Figure 2). Regarding with the purpose of using the current LARC, 129 (79.6\%) of were used the method for spacing and 33 (20.3\%) of them were used for limiting purpose. One hundred forty four (88.9\%) of the current users were informed about possible side effect of the LARC method currently they used and the remaining 18 (11.1\%) them were not informed. One hundred fifty six (96.3\%) the current users were satisfied with the method they used and only 6 (3.7\%) of them were unsatisfied with the method they received.

\subsection{Determinants for LARC Method Use}

Bivariate analysis was used to assess determinants of LARC method use among mothers in extended postpartum period. Educational level of mothers in extended postpartum period had significant association in the use of LARC. The odds of mother who completed secondary level of education (9 - 12 grade) were 4.09 times more likely to use LARC compared to those who were completed primary education and/or illiterate mothers (AOR = 4.09; 95\% CI:1.68,9.58, $P$ value $<0.001$ ). Previous history of use of LARC was found statistically significant as determinant factor for current use of similar methods. The odds of those mothers who had ever used LARC methods were 7.84-fold adopted LARC than those mothers who were not used previously (AOR $=7.8495 \%$ CI: $3.78,16.23, P$ value $<0.001)$.

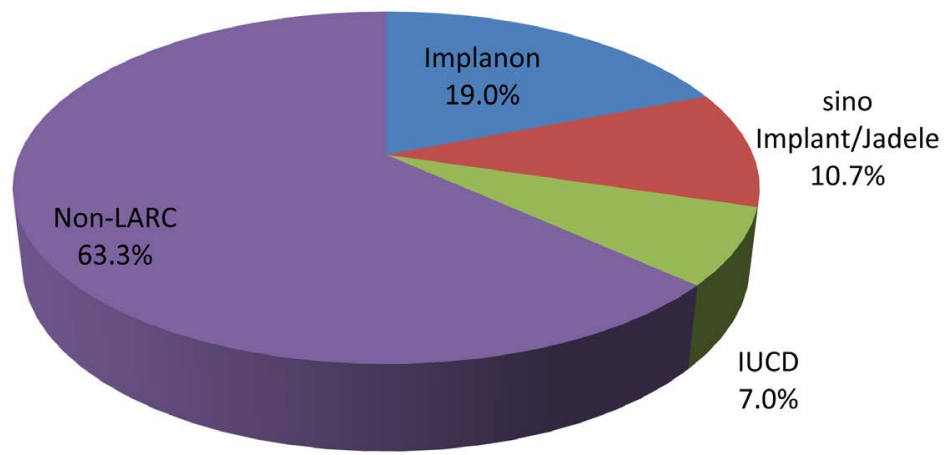

Figure 1. Pie chart showing current users and non users of LARC methods among mothers during extended postpartum period, Durame town, 2015. 


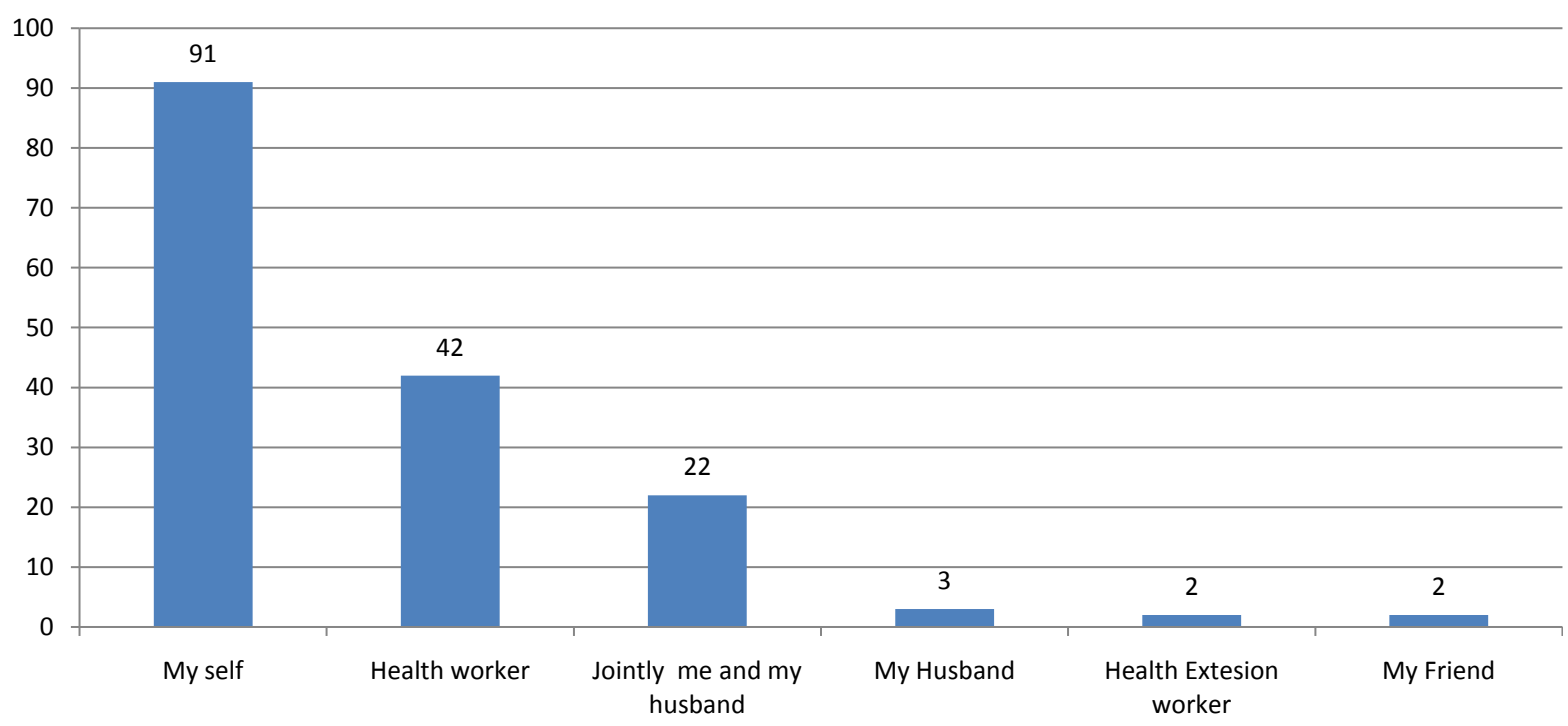

Figure 2. Bar chart showing decision making in selecting LARC method among mothers who are currently using LARC in Durame town, 2015.

Mothers who received counseling services on LARC method during delivery service were found 3.28 times higher in using the contraception than those mothers who weren't counseled (AOR $=3.29$; 95\% CI: 1.53, 7.03, $P$-value $<0.05)$. Similarly; counseling service on LARC during immediate postpartum period were found statistically significant in determining the uptake of LARC methods. Those mothers who were counseled on LARC methods during immediate postpartum period was up to five times more likely to adopt LARC methods compared to those mothers who were not counseled (AOR $=4.58$; 95\% CI: 1.94, 10.66, $P$ value $<0.001$ ) (Table 5).

\section{Discussions}

This study was conducted in an attempt to identify determinants of LARC method use among mothers in extended postpartum period, Durame town administration, South Ethiopia. We found that one third of mother in extended postpartum period was 36.7\% (95\% CI: 32.2, 41.5) LARC methods user. Similar finding (28.4\%) was documented by Mota et al. in Oromia Region of Ethiopia among reproductive age group mothers who visit health facilities for family planning service [16]. However, this finding was much higher than a national based estimates 6.1\% of women use LARC as reported in Ethiopian mini DHS, (2014) [17]. This may be due to two reasons. First it might be due the difference in the residence of the study population, in this study mothers mainly reside in urban setting. The second one might be due to initiatives of the government of Ethiopia to scale up access to charge free LARC services at community and health facility level. Health Extension Workers are expected to insert implant and Nurse to insert IUCD at community health post and Health Centers or Hospital level, respectively.

In this study, the unmet family planning need of mothers in the extended postpartum period was 123 (27.9\%). This finding was in line with the unmet need range from $25 \%$ to $90 \%$ generated from five countries using reports of over 100 active surveillance sites for mothers in postpartum period [18].

In this study, the mix of LARC method used among mothers in extended period includes; $19 \%$ were Implanon, $10.7 \%$ were Jadelle/Sino Implant and 7\% were IUCD. The utilization of IUCD is 7\% among mothers in extended postpartum period which is less than that of (10\%) reported in Afghanistan; on integrating family planning into postpartum care through Modern Quality Improvement [19]. This may be due socio-cultural difference in the two study areas.

The educational status of mothers was significantly associated with the utilization LARC. The odds of mothers who completed secondary level of education were up to 4.02 fold utilize LARC methods compared to those mothers whose education were in primary level and/or illiterate. This finding was similar to that of a study conducted in rural Bareilly, India [20]. Mothers who ever used LARC method previously were found 7.84 times more likely to use LARC than mothers who never use it. This finding was much higher than the reported odds of 
Table 5. Determinants for use of LARC methods among mothers in extended postpartum period, Durame town administration, 2015.

\begin{tabular}{|c|c|c|c|c|}
\hline \multirow{2}{*}{ Variable } & \multicolumn{2}{|c|}{ LARC use } & \multirow[b]{2}{*}{ COR $(95 \% \mathrm{CI})$} & \multirow[b]{2}{*}{ AOR (95\% CI) } \\
\hline & Yes & No & & \\
\hline \multicolumn{5}{|l|}{ Education of participant } \\
\hline Primary (1 - 8) and less & 35 & 165 & 1 & 1 \\
\hline Secondary $(9-12)$ & 87 & 73 & $5.61(3.47900)^{* *}$ & $4.09(1.68958)^{* *}$ \\
\hline Above secondary & 40 & 41 & $4.59(2.60811)^{* *}$ & $1.73(0.53565)$ \\
\hline \multicolumn{5}{|l|}{ Education of husband } \\
\hline Primary $(1-8)$ and Less & 35 & 121 & 1 & 1 \\
\hline Secondary $(9-12)$ & 58 & 81 & $2.47(1.49410)^{* *}$ & $1.11(0.41296)$ \\
\hline Above secondary & 69 & 74 & $3.22(1.95531)^{* *}$ & $2.03(0.62661)$ \\
\hline \multicolumn{5}{|l|}{ Occupation of husband } \\
\hline None employed & 33 & 102 & 1 & 1 \\
\hline Self employed & 62 & 92 & $2.08(1.25346)^{*}$ & $1.05(0.3299)$ \\
\hline Employed & 67 & 82 & $2.52(1.51419)^{* *}$ & $0.43(0.13137)$ \\
\hline \multicolumn{5}{|c|}{ Availability of electronic media } \\
\hline None of TV or radio & 12 & 95 & 1 & 1 \\
\hline Radio & 38 & 80 & $3.76(1.84767)^{* *}$ & $2.50(0.76821)$ \\
\hline TV & 33 & 42 & $6.22(2.921322)^{* * *}$ & $2.50(0.66937)$ \\
\hline Both TV \& radio & 79 & 62 & $10.08(5.072003)^{* *}$ & $2.96(0.811077)$ \\
\hline \multicolumn{5}{|l|}{ Previous use of LARC } \\
\hline No & 75 & 240 & 1 & 1 \\
\hline Yes & 87 & 39 & $7.13(4.511128)^{* *}$ & $7.84(3.781623)^{* *}$ \\
\hline \multicolumn{5}{|l|}{ Number of ANC visit } \\
\hline Less than four times & 21 & 71 & 1 & 1 \\
\hline Four and above times & 141 & 203 & $2.34(1.37399)^{*}$ & $2.21(0.80560)$ \\
\hline \multicolumn{5}{|c|}{ Counsel about LARC during ANC visit } \\
\hline No & 58 & 151 & 1 & 1 \\
\hline Yes & 104 & 123 & $2.20(1.47328)^{* *}$ & $0.91(0.45187)$ \\
\hline \multicolumn{5}{|c|}{ Counseled on LARC during delivery } \\
\hline No & 26 & 132 & 1 & 1 \\
\hline Yes & 136 & 132 & $5.23(3.22848)^{* *}$ & $3.29(1.53703)^{*}$ \\
\hline \multicolumn{5}{|c|}{ Counseled on LARC during immediate postpartum period } \\
\hline No & 10 & 103 & 1 & 1 \\
\hline Yes & 80 & 114 & $7.22(3.551469)^{* *}$ & $4.55(1.941066)^{* *}$ \\
\hline
\end{tabular}

${ }^{* *} P<0.001 ;{ }^{*} P<0.05$. 
use LARC (4.53) among women in Mana district, Jimma zone, South West Ethiopia. This could be due to the fact that experienced mothers acquired the necessary knowledge and attitude towards LARC method, while other could be influenced by myths and misconceptions. The other reason could be the difference of study settings; our study focuses urban setting, while the Mana district focused on rural areas [21].

Similarly counseling on LARC methods during delivery and immediate postpartum period were found significantly associated with LARC use. The odds of mothers who were received counseling service on LARC methods during delivery were 3.28 times more likely to use LARC contraception than mothers who weren't counseled. Likewise, mothers who were counseled on LARC methods during immediate postpartum period were 4.57 times higher in using LARC than those mothers who weren't counseled. This was similar with the finding of the study conducted in Mexico [22].

\section{Limitation}

This study was conducted in town administration; the findings couldn't be used to generalize for mother in rural places.

\section{Conclusion}

In the study area, one third of mothers were using LARC method during their extended postpartum period. Despite this very good level of service uptake, there was a comparable prevalence of unmet family planning need. Educational status of mothers, previous use of LARC, counseling on LARC during delivery and immediate postpartum period were the main determinants factors for uptake of LARC methods among mothers in extended postpartum period. Empowering women through formal education, maintaining provision of health information and access to LARC methods mix counseling service during antenatal, delivery and postnatal services was highly recommended.

\section{Acknowledgements}

We are thankful for all participant mothers for their time and invaluable responses.

\section{Authors' Contribution}

YET and EG initiated the research, wrote the research proposal, conducted the research and did data entry and analysis. MDA involved in conceptualization of the research, statistical analysis and writing of the manuscript. All authors read and approved the final manuscript.

\section{References}

[1] DaVanzo, J., Hale, L., Razzaque, A. and Rahman, M. (2007) Effects of Inter Pregnancy Interval and Outcome of the Preceding Pregnancy on Pregnancy Outcomes in Matlab, Bangladesh. BJOG: An International Journal of Obstetrics \& Gynecology, 114, 1079-1087. http://dx.doi.org/10.1111/j.1471-0528.2007.01338.x

[2] Ross, J.A. and Winfrey, W.L. (2001) Contraceptive Use, Intention to Use and Unmet Need during the Extended Postpartum Period. International Family Planning Perspectives, 27, 20-27. http://dx.doi.org/10.2307/2673801

[3] Shaaban, O. and Glasier, A. (2008) Pregnancy during Breastfeeding in Rural Egypt. Contraception, 77, 350-354. http://dx.doi.org/10.1016/j.contraception.2008.01.005

[4] Cleland, J., Bernstein, S., Ezeh, A., Faundes, A., Glasier, A. and Innis, J. (2006) Family Planning: The Unfinished Agenda. The Lancet, 368, 1810-1827. http://dx.doi.org/10.1016/S0140-6736(06)69480-4

[5] David, H., Iphigeneia, M. and Erin, M. (2008) Unintended Pregnancy in Sub-Saharan Africa: Magnitude of the Problem and Potential Role of Contraceptive Implants to Alleviate It. Contraception, 78, 73-78. http://dx.doi.org/10.1016/j.contraception.2008.03.002

[6] Population Division of the Department of Economic and Social Affairs of the United Nations Secretariat (2013) World Contraceptive Patterns 2013. United Nations, New York.

[7] Maternal and Child Health Intergradation Program (2013) Family Planning Needs during the First Two Years Postpartum in the Ethiopia. USAID.

[8] Espey, E. and Ogburn, T. (2011) Long-Acting Reversible Contraceptives Intrauterine Devices and the Contraceptive Implant. Clinical Expert Series, 117, 705-719. 
[9] Central Statistical Agency [Ethiopia] and ICF International (2012) Ethiopian Demographic and Health Survey (EDHS) 2011. Addis Ababa, Ethiopia and Calverton, Maryland, USA.

[10] Brooke, W., Jeffrey, F., Peipert, Q., Christina, B., Tessa, M., Jenifer, E. and Gina, M. (2012) Effectiveness of LongActing Reversible Contraception. The New England Journal of Medicine, 366, 1998-2007.

[11] Gaffield, M.E., Egan, S. and Temmerman, M. (2014) It’s about Time: WHO and Partners Release Programming Strategies for Postpartum Family Planning. Global Health, Science and Practice, 2, 4-9. http://dx.doi.org/10.9745/GHSP-D-13-00156

[12] Federal Ministry of Health (2010) Health Sector Development Program IV (2010/2011 to 2014/2015). Federal Ministry of Health, Addis Ababa.

[13] Population Census Commission, Federal Democratic Republic of Ethiopia (2008) Summary and Statistical Report of the 2007 Population and Housing Census. PCC, Addis Ababa.

[14] Durame Town Health Office (2014) Annual Health Report. Durame Town Health Office, Durame.

[15] Bartlett, J.E., Kotrlik, J.W. and Higgins, C.C. (2001) Organizational Research: Determining Appropriate Sample Size in Survey Research. Information Technology, Learning, and Performance Journal, 19, 43-50.

[16] Mota, K., Reddy, S. and Getachew, B. (2015) Unmet Need of Long-Acting and Permanent Family Planning Methods among Women in the Reproductive Age Group in Shashemene Town, Oromia Region, Ethiopia: A Cross Sectional Study. BMC Women's Health, 15, 51. http://dx.doi.org/10.1186/s12905-015-0209-y

[17] Central Statistical Agency [Ethiopia] (2014) Ethiopia Mini Demographic and Health Survey 2014. Addis Ababa.

[18] Pasha, O., Goudar, S.S., Patel, A., Garces, A., Esamai, F., Chomba, E., Moore, J.L., Kodkany, B.S., Saleem, S., Derman, R.J., Liechty, E.A., Hibberd, P.L., Hambidge, K.M., Krebs, N.F., Carlo, W.A., McClure, E.M., Koso-Thomas, M. and Goldenberg R.L. (2015) Postpartum Contraceptive Use and Unmet Need for Family Planning in Five Low-Income Countries. Reproductive Health, 12, S11. http://dx.doi.org/10.1186/1742-4755-12-s2-s11

[19] Tawfik, Y., Rahimzai, M., Ahmadzai, M., Clark, P.A. and Kamgang, E. (2013) Integrating Family Planning into Postpartum Care through Modern Quality Improvement: Experience from Afghanistan. Global Health: Science and Practicee, 2, 226-233. http://dx.doi.org/10.9745/GHSP-D-13-00166

[20] Mahmood, S.E., Srivastava, A., Shrotriya, V.P., Shaifali, I. and Mishra, P. (2011) Postpartum Contraceptive Use in Rural Bareilly. Indian Journal of Community Health, 23, 56-57.

[21] Dibaba, Y. (2010) Child Spacing and Fertility Planning Behavior among Women in Mana District, Jimma Zone, South West Ethiopia. Ethiopian Journal of Health Science, 20, 83-90.

[22] Barber, S.L. (2007) Family Planning Advice and Postpartum Contraceptive Use among Low-Income Women in Mexico. International Family Planning Perspectives, 33, 6-12. http://dx.doi.org/10.1363/3300607 